\title{
Translation and psychometric properties of the German version of the University of the West of England Interprofessional Questionnaire (UWE-IP).
}

Abstract: (max 200 words, no subheadings)

The implementation of a bachelor degree in Interprofessional Health Care at the University of Heidelberg, Germany has fostered the need to evaluate the impact of this innovative programme. The University of the West of England Interprofessional questionnaire (UWE-IP) was developed by Pollard et al. in 2004 for longitudinal evaluation of an interprofessional curriculum. The UWE-IP consists of 35 items in 4 scales "Communication and Teamwork Scale", "Interprofessional Learning Scale", "Interprofessional Interaction Scale" and "Interprofessional Relationships Scale". The UWE-IP was translated to German according to international guidelines. To assess psychometrics reliability of the four scales was tested with Cronbach's Alpha. Confirmatory factor analysis was performed to examine the underlying factor structure. The sample consisted of 326 datasets. Reliability for the scales was between 0.75 and 0.90 . The underlying factor structure showed a good fit. We conclude that the German UWE-IP shows good psychometrics and recommend its use for of evaluation of interprofessional learning activities. These results add to the body of knowledge on evaluation instruments in interprofessional education.

(167 words) 


\section{Translation and psychometric properties of the German version of the University of the West of England Interprofessional Questionnaire (UWE-IP).}

\section{Introduction}

Interprofessional education and learning activities in health care are increasingly being introduced worldwide to promote interprofessional collaboration in the workplace. In Germany, an interprofessional bachelor degree for health professionals was introduced in 2011 at the University of Heidelberg for nine different health professions. Parallel to their vocational training (either in Geriatric, General or Pediatric Nursing; Physiotherapy; Speech and Language Therapy; Midwifery; Orthoptics; Medical Technical Laboratory Assistants and Medical Technical Radiography Assistants) students are able to complete a Bachelor of Science "Interprofessional Health Care“, achieving two qualifications after four and a half years via a formally endorsed programme (Mahler et al., 2015). The establishment of the interprofessional curriculum, led to the search for appropriate evaluation tools in order to assess if the degree demonstrates the expected impact and to adapt educational settings so that students acquire the required competencies (Freeth, Hammick, Koppel, Reeves, \& Barr, 2002).

The University of the West of England Interprofessional Questionnaire (UWE-IP) is a self-report instrument to assess attitudes of health professionals. It was developed by Pollard and colleagues and resulted in a set of four scales addressing different themes and for administration at different stages in training/education (K. Pollard, Miers, \& Gilchrist, 2005; K. C. Pollard, Miers, \& Gilchrist, 2004). The four scales are: "Communication and Teamwork Scale" (9 items), "Interprofessional Learning Scale" 
(9 items), "Interprofessional Interaction Scale" (9 items) and "Interprofessional Relationships Scale" (8 items). The items are measured on a four-point (communication and teamwork scale) or five-point Likert scale with $1=$ strongly agree, $2=$ agree, $3=$ undecided, $4=$ disagree, and $5=$ strongly disagree. The UWEIP has shown content validity and reliability in English at acceptable levels across multiple health professions (Bruner, Waite, \& Davey, 2011; King et al., 2014; K. Pollard et al., 2005; Ruebling et al., 2014). It has been used in the pre-post evaluation of a wide range of interprofessional education and learning activities (Kenaszchuk, Rykhoff, Collins, McPhail, \& van Soeren, 2012; Ruebling et al., 2014). Furthermore the UWE-IP has been implemented as a regular evaluation tool for IPE workshops at Curtin University, Perth Australia (Curtin University, 2011)

Translations of the UWE-IP into Slovenian and Arabic have shown reliability with Cronbach's alpha ranging between 0.64 and 0.91 for the various scales (Alshaikh, 2015; Pahor, 2008). Having shown reliability across various health professions, settings and languages a German version of the UWE-IP was regarded as necessary in order to be able to compare results internationally . The aim of this paper is to describe the translation process of the UWE-IP into German and to demonstrate reliability and factor structure of the translated German instrument.

\section{Methods}

Translation process

Permission for translation was obtained from the instrument developer and translation was performed according to international guidelines (Acquadro, Conway, Hareendran, \& Aaronson, 2008) using forward backward translation. The UWE-IP was translated individually from English to German by two people with a health care 
background (Psychologist $[\mathrm{KK}]$ and Nurse $[\mathrm{CM}]$ ). Both versions were reconciled and synthesized into one version. During the reconciliation process, questions arose in the conceptualization of individual items. For example, what is the difference between the terms "students", "health care students" and "other health care students"? i.e. In which items do they refer to students of other health care disciplines, when to students in general, and when to students of the same discipline? Also, items 5 and 8 refer to "skills" that the students attain. The translators were not quite sure whether to translate for the sense of "skills" or rather "competencies". Such questions were solved with the original instrument developers and German wording was adapted accordingly.

The reconciled German version was then translated back to English individually by two nurses with English as their mother tongue ([SB] and [SR]), who in a second step reconciled their back translated English language version. This reconciled English version was then sent to the instrument developer [KP] who approved the instrument back translation and confirmed that the underlying concepts had been maintained. Finally, the German version of the UWE-IP (UWE-IP-D) was then handed to eight health professionals (medicine, nursing and physiotherapy) with clinical experience for a cognitive interview (think aloud) to verify understanding of the items and to refine wording.

\section{Participants}

The German version of the UWE-IP was then administered in two independent surveys:

a) All four scales of the UWE-IP-D were administered in an online-survey of 437 health care professionals (Geriatric, General and Pediatric Nursing; Physiotherapy; Speech and Language Therapy; Midwifery; Orthoptics; Medical Technical Laboratory 
Assistants and Medical Technical Radiography Assistants) who had been in clinical practice approximately one year post qualification. Graduates had completed their vocational training at the Academy of Health Professions of the University Hospital. These graduates received an email with the link to the online survey and a reminder three weeks later. The complete survey also included other scales measuring work satisfaction, research utilization, self-efficacy as well as socio-demographic data. b) In addition, two scales "Communication and Teamwork Scale" and “Interprofessional Learning Scale" were administered as a paper-pencil survey to 145 medical students and 20 healthcare students of the interprofessional bachelor degree prior to a seminar on team communication.

Ethical approval was received from the University of Heidelberg Medical Faculty Ethics Committee for the online survey. Data collected from the medical and health care students was for quality assurance reasons within a pilot seminar within the Medical Faculty. Both samples had not been exposed to interprofessional learning activities before filling in the questionnaire.

\section{Statistics}

UWE-IP-D Items were reverse scored according to Pollard 2005 and merged to test psychometrics. Descriptive statistical analysis was carried out to assess participant characteristics in each sample as well as item and scale characteristics of the UWEIP-D. Continuous data were summarized by using means $(M)$ and standard deviations (SD), categorical data by using frequency counts and percentages. Differences regarding participant characteristics were analysed with Chi-square Test. 
Cronbach's alpha was used to determine internal consistency of the each scale.

Finally, confirmatory factor analysis (CFA) was conducted to assess the factor structure of the German version of the UWE-IP. The following indicators were used to evaluate the fit of the 4 scales of the UWE-IP: Chi-square goodness-of-fit statistic (unnormed and normed by degrees fo freedom), Comparative Fit Index (CFI), Tucker-Lewis Index (TLI) and root mean square error of approximation (RMSEA). IBM SPSS Statistics (Version 20, Chicago, IL, USA) was used to calculate descriptive statistics and to perform reliability analysis. Confirmatory factor analysis was done with IBM SPSS AMOS 22 (IBM SPSS AMOS for Windows, Version 22.0. Armonk, NY: IBM Corp.; 2013)

\section{Results}

Sample

a) All four scales of the German UWE-IP were completed by 158 graduates in the online-survey (response rate $36.2 \%$ ) of which 149 graduates indicated sociodemographic characteristics. Most respondents were female $\mathrm{N}=129(86.6 \%)$ and about half were under 25 years old $(\mathrm{N}=81 ; 54 \%)$ (see table 1$)$.

b) The "Communication and Teamwork" and "Interprofessional Learning" scales of the UWE-IP were completed by 165 students (145 medical and 20 interprofessional health care students). Nearly half the students were female 72 (43.6\%). Most students were under 25 years old $(N=134 ; 81.2 \%)$ (see table 1). Significant differences between samples were detected regarding age $(p<0.001)$ and gender $(p$ $<0.001)$. 
Table 1: Socio demographic Characteristics

\begin{tabular}{|c|c|}
\hline Online Survey (Graduates) & $\mathrm{N}=158(100 \%)$ \\
\hline Nursing & $72(48.1)$ \\
\hline Midwifery & $21(13.3)$ \\
\hline Physiotherapy & $14(8.9)$ \\
\hline Speech LanguageTherapy & $7(4.4)$ \\
\hline Med Tech Laboratory Assistants & $13(8.2)$ \\
\hline $\begin{array}{l}\text { Med Tech Radiography } \\
\text { Assistants }\end{array}$ & $18(11.4)$ \\
\hline Missing & $9(5.7)$ \\
\hline Age & $\mathrm{N}=149(100 \%)$ \\
\hline$<25$ & $81(54.0)$ \\
\hline $25<30$ & $61(40.7)$ \\
\hline Gender & $\mathrm{N}=149(100 \%)$ \\
\hline male & $20(13.4)$ \\
\hline female & $129(86.6)$ \\
\hline Paper-Pencil Survey (Students) & $\mathrm{N}=165(100 \%)$ \\
\hline Medicine & $145(87.9)$ \\
\hline Interprofessional Health Care & $20(12.1)$ \\
\hline Age & $\mathrm{N}=164(100 \%)$ \\
\hline$<25$ & $134(81.2)$ \\
\hline $25<30$ & $25(15.2)$ \\
\hline Gender & $\mathrm{N}=165(100 \%)$ \\
\hline male & $93(56.4)$ \\
\hline female & $72(43.6)$ \\
\hline
\end{tabular}

Scale characteristics and internal consistency

Item discrimination and Cronbachs alpha values for the four scales are displayed in table 2. Item discrimination values are in the desired range with no value $<0.20$. All scales of the UWE-IP-D showed good to very good internal consistency with Cronbachs alpha ranging from 0.75 to 0.90 . 
Table 2: Item discrimination of the UWE-IP-D and internal consistency of the German version, the original version and translations to Slowenian and Arabic.

\begin{tabular}{|c|c|c|c|c|c|}
\hline & $\begin{array}{c}\text { Item } \\
\text { discrimination } \\
\text { UWE-IP-D }\end{array}$ & $\begin{array}{l}\text { Internal } \\
\text { consistency } \\
\text { UWE-IP-D }\end{array}$ & $\begin{array}{c}\text { Internal } \\
\text { consistency } \\
\text { UWE-IP } \\
\text { (Pollard } \\
2004 \& \\
2005 \text { ) }\end{array}$ & $\begin{array}{c}\text { Internal } \\
\text { consistency } \\
\text { UWE-IP } \\
\text { (Pahor 2008, } \\
\text { Slowenian) }\end{array}$ & $\begin{array}{c}\text { Internal } \\
\text { consistency } \\
\text { UWE-IP } \\
\text { (Alshaikh } \\
2015, \\
\text { Arabic) }\end{array}$ \\
\hline $\begin{array}{l}\text { Teamwork and } \\
\text { Collaboration } \\
(\mathrm{N}=305)\end{array}$ & $.37-.49$ & .75 & .76 & .83 & .64 \\
\hline $\begin{array}{l}\text { Interprofessional } \\
\text { Learning } \\
(\mathrm{N}=312)\end{array}$ & $.50-.81$ & .90 & .84 & no data & .89 \\
\hline $\begin{array}{l}\text { Interprofessional } \\
\text { Interactions } \\
(\mathrm{N}=144)\end{array}$ & $.27-.65$ & .80 & .82 & .88 & .82 \\
\hline $\begin{array}{l}\text { Interprofessional } \\
\text { Relationship } \\
(\mathrm{N}=144)\end{array}$ & $.32-.73$ & .81 & .71 & .91 & .66 \\
\hline
\end{tabular}

Confirmatory factor analysis (CFA)

The CFA model is displayed in figure 1 showing the resulting estimates for the 4 scale model of the overall dataset. The model showed a good model fit regarding the normed Chi-squared $\left(x^{2}[554, n=323]=1146.673, p<0.001, x^{2} / d f=2.070\right)$. The 
RMSEA showed a value of 0.058 being a good fit. The CFI (0.800) and TLI (0.773) did not show a good fit not quite reaching a value of 0.9 . The scale "Interprofessional Relationship" shows a relative high correlation $>0.5$ with the "Communication and Teamwork " and "Interprofessional Interaction" scales. Standardised factor loadings are all $\geq 0.4$ with the exception of item 7 in the „Interprofessional Interaction” scale ("Not all relationships between health and social care professionals are equal"), with a value of 0.31

\section{Discussion}

This study presents the translation process and adaptation the UWE-IP into German in a sample of health care students and graduates. The instrument shows good reliability and replicates the factor structure of the original version of the UWE-IP in the confirmatory factor analysis.

The translation shows similar values of internal consistency compared to the original version (K. C. Pollard et al., 2004) as well as to the studies by (Bruner et al., 2011; Ruebling et al., 2014) and the other translations (Alshaikh, 2015; Pahor, 2008). Although the factor structure was replicated, high correlation between individual scales was found indicating that these scales may not represent different dimensions. However being a long instrument when administering all four scales, this may allow omitting one of the scales, all depending on the focus of the evaluation.

Differences in age are expected as graduates are typically older than students. Reasons for differences in gender are due to the fact that health care professions tend to be female dominated. The population can therefore be regarded as a good cross-sectional sample. 
Limitations: The sample size for the scales "Interprofessional Interaction" and "Interprofessional Relationship" were not identical with that of the other scales. In addition the questionnaire was administered in different ways: About half the sample filled in the survey online, the medical students only filled in the questionnaire as a paper-pencil survey. The mode of administration may effect the results. The sample consisted of both graduates and students leading to different experience levels in clinical and/or interprofessional settings. Using self-report instruments is always a challenge when measuring interprofessional outcomes.

\section{Conclusion}

The German version of the UWE-IP (UWE-IP-D) is a reliable instrument that represents the scale dimension of the original version. We conclude that it can be used in Germany to evaluate interprofessional courses, ensure quality and help compare and develop appropriate interprofessional teaching environments. Further studies and analysis of the psychometrics of the UWE-IP are recommended to verify and sharpen the scale dimensions. These results add to the body of knowledge on evaluation instruments in interprofessional education.

\section{(1612 words)}

Acknowledgements: We would like to thank Susi Richter [SR] who performed the back translation of the reconciled German Version into English.

Declaration of interest: The authors report no conflicts of interest. The authors alone are responsible for the content and writing of the article. 


\section{References}

Acquadro, C., Conway, K., Hareendran, A., \& Aaronson, N. (2008). Literature review of methods to translate health-related quality of life questionnaires for use in multinational clinical trials. Value Health, 11(3), 509-521.

Alshaikh, S. J. (2015). Measuring Healthcare Undergraduate Students' Attitudes to Interprofessional Education and collaborative practice in Saudi Arabia: The Validation of an Arabic version of the University of West England Interprofessional Questionnaire Paper presented at the 5Th European Conference on Interprofessional practice \& Education (5th EIPEN) Nijmegen, Netherland.

Bruner, P., Waite, R., \& Davey, M. P. (2011). Providers' perspectives on collaboration. Int J Integr Care, 11, e123.

Curtin University, F. o. H. S. (2011). Report. 2011 Interprofessional Education Workshops. Retrieved from http://healthsciences.curtin.edu.au/local/docs/2011_IPE_Workshops_Report.pdf

Freeth, D., Hammick, M., Koppel, I., Reeves, S., \& Barr, H. (2002). A Critical Review of Evaluations of Interprofessional Education Occasional Paper No. 2. Retrieved from http://www.health.heacademy.ac.uk/rp/publications/occasionalpaper

Kenaszchuk, C., Rykhoff, M., Collins, L., McPhail, S., \& van Soeren, M. (2012). Positive and null effects of interprofessional education on attitudes toward interprofessional learning and collaboration. Adv Health Sci Educ Theory Pract, 17(5), 651-669. doi: 10.1007/s10459-011-9341-0

King, S., Carbonaro, M., Greidanus, E., Ansell, D., Foisy-Doll, C., \& Magus, S. (2014). Dynamic and routine interprofessional simulations: expanding the use of simulation to enhance interprofessional competencies. J Allied Health, 43(3), 169-175.

Mahler, C., Berger, S. J., Karstens, S., Campbell, S., Roos, M., \& Szecsenyi, J. (2015). Reprofiling today's health care curricula for tomorrow's workforce: Establishing an interprofessional degree in Germany. J Interprof Care, 29(4), 386-388. doi: $10.3109 / 13561820.2014 .979980$

Pahor, M. (2008). Interprofessional relationships: doctors and nurses in Slovenia. In E. Kuhlmann \& M. Saks (Eds.), Rethinking professional governance: International directions in health care. Bristol: Policy Press.

Pollard, K., Miers, M. E., \& Gilchrist, M. (2005). Second year scepticism: pre-qualifying health and social care students' midpoint self-assessment, attitudes and perceptions concerning interprofessional learning and working. J Interprof Care, 19(3), 251-268. doi: $10.1080 / 13561820400024225$

Pollard, K. C., Miers, M. E., \& Gilchrist, M. (2004). Collaborative learning for collaborative working? Initial findings from a longitudinal study of health and social care students. Health Soc Care Community, 12(4), 346-358. doi: 10.1111/j.1365-2524.2004.00504.x

Ruebling, I., Pole, D., Breitbach, A. P., Frager, A., Kettenbach, G., Westhus, N., . . Carlson, J. (2014). A comparison of student attitudes and perceptions before and after an introductory interprofessional education experience. J Interprof Care, 28(1), 23-27. doi: $10.3109 / 13561820.2013 .829421$ 